\title{
EC look to animal patents
}

\section{London}

SIx years after a patent application for the genetically engineered 'Harvard mouse' was submitted to the European Patent Office - and two years after the same patent was granted in the United States the application still languishes in a legal quagmire of moral and procedural debate over the patenting of life forms in Europe. But a decision next month in Brussels may mean that the end is in sight. In the session beginning on 7 October, the European Parliament legal affairs committee is expected to approve a draft directive "on the legal protection of biotechnological inventions" that would explicitly allow the patenting of bioengineered life forms everything from a gene to an entire animal - in the nations of the European Communities (EC).

If the directive is indeed approved, it will be voted on by the full Parliament, and then go to the Council of Ministers, which will make a final decision based on the parliamentary recommendation and the proportions of the vote. But before the directive emerges, legislators must navigate their way through a hail of ethical and legal arguments from outspoken opponents of animal patenting.

Unlike countries such as the United States, Canada and Hungary, where patents for plants are permitted, Europe's current Patent Convention does not generally allow for property rights over plants and animals. Any exception requires a protracted legal battle - the Harvard mouse imbroglio, for example - or new legislation, as is now being considered in Brussels.

Both the proposed EC legislation and the current intellectual property rights negotiations at the General Agreement on Tariffs and Trade (GATT) world trade talks in Geneva seek to bring US-style biotechnology protection to the rest of the world. In favour of these efforts, industry organizations such as the London-base BioIndustry Association argue that Europe's biotechnology industry will continue to lag behind that of the United States until its patent laws are equally strong. "Both investment and the progress of research will be concentrated in those countries that offer the best incentives, especially patent protection," says executive director Louis De Gama.

But opponents of the legislation are loud and organized. They argue that patents for genetically engineered plants and animals will decrease genetic diversity, slow the free exchange of scientific knowledge, raise ethical problems such as the morality of monopoly ownership of living things, and increase animal suffering.

One of the strongest voices of dissent comes from the developing nations, which argue that much of the raw genetic stock of agricultural biotechnology — genes from disease- and pest-resistant plants that can be inserted into other species - have come from their natural resources. As Western companies get rich from new bioengineered plants, they say, the work of the West African farmers who raised the original insect-resistant cowpeas and the Bolivian farmers who bred diseasefree potatoes is being looted. "Genetic resources must be considered as our common shared heritage" said Ed Mayo of the World Development Movement last spring, when more than 30 European environmental, animal welfare and agricultural groups organized by the Londonbased Genetics Forum urged the rejection of the directive. Both the Genetics Forum and the BioIndustry Association are preparing to launch another lobbying campaign this month to shift the EC debate their own way. Christopher Anderson

\section{HDTV satellite is up}

\section{Tokyo}

OPERATORS of Japan's satellite television breathed a sigh of relief Sunday after the successful launch of a new broadcasting satellite by the National Space Development Agency. The satellite has a channel to broadcast High Definition Television (HDTV) and will also provide vital backup for a companion satellite that is limping along on reduced power.

Satellite television has been on the brink of collapse in Japan after two broadcasting satellites - one aboard a European Ariane rocket, the other on a US craft were blown up shortly after lift-off due to malfunctions of the rockets. Adding to these woes was a malfunction of the BS- 3a satellite launched by the space agency last year, which has only about 75 per cent power because of a defect in its solar panels.

In addition to backing up the BS-3a, the new satellite will enable Japan's national broadcasting company to extend test transmissions of HDTV from about one to eight hours a day, and Japan Satellite Broadcasting Inc. will introduce the world's first commercial HDTV transmissions with the satellite - all of which should help nurture Japan's fledgling HDTV industry. But with HDTV sets currently priced at about $\$ 30,000$ apiece, no one expects a rush of new customers yet. David Swinbanks

\section{First the moon, now Mars}

\section{Tokyo}

There seems to be no limit to the ambitions of Japan's little academic space institute, the Institute of Space and Astronautical Science (ISAS). Having sent a probe to the Moon last year, ISAS scientists are now planning to stretch their technology to its limits and send a modest mission to Mars in 1996.

Earlier ISAS plans had been more conservative and had called for a mission to Venus after a follow-up expedition to the Moon in 1995 (Nature 344, 693; 1990). At the time, Mars was considered to be beyond the range of the institute's nextgeneration $\mathrm{M}-\mathrm{V}$ rocket, which is currently under development.

But ISAS scientists now believe they can reach Mars with the $M \cdot V$ by using a smaller probe with its spin axis and communication antenna and solar panels constantly pointed towards the Earth. A fortuitous alignment of the Sun, Earth and Mars will allow the probe to catch sufficient solar power without having to align the solar panels directly towards the Sun and without having to install heavy steering equipment for the communication antenna.

The saving in weight will amount to 50 $\mathrm{kg}$, bringing the total probe weight down to $250 \mathrm{~kg}$ (excluding fuel) - light enough that the little M-V solid fuel rocket will be able to push the probe all the way to Mars. But the light-weight probe will only be able to carry a very small scientific payload of about $40 \mathrm{~kg}$. In contrast, the Soviet Union is planning to send a 2-ton payload to Mars in 1994 - nearly 50 times as heavy as the Japanese probe will carry - and the United States will send a probe with about a 1-ton payload next year.

Koichiro Tsuruda of ISAS says Venus and Mars are equally interesting for scientists, but ISAS has chosen Mars as the first planetary target because its upper atmosphere is less studied than that of Venus. If all goes according to plan, the Mars probe, called Planet B, should arrive at Mars in September 1997 and will orbit the planet at distances ranging from 150 to 34,000 $\mathrm{km}$. The main scientific objective will be to study the Martian upper atmosphere and its interaction with the Solar wind, Tsuruda says.

The light-weight Mars probe can be built for only about $\$ 80$ million, with an additional \$40 million or so for the M-V launcher, Tsuruda says. In contrast, the US and Soviet Mars missions are expected to cost hundreds of millions of dollars. The Ministry of Education, Science and Culture has just requested about $¥ \mathbf{1 0 0}$ million $(\$ 740,000)$ for Planet $B$ in the budget for next fiscal year.

David Swinbanks 